\title{
LeVERAgINg EsCAPE RoOM POPUlARITY To PROVIDE FIRST- YEAR STUDENTS WITH AN INTRODUCTION TO ENGINEERING INFORMATION
}

\author{
Benjamin Walsh, Michelle Spence \\ University of Toronto \\ benjamin.walsh@utoronto.ca, michelle.spence@utoronto.ca
}

\begin{abstract}
Incoming first-year engineering students at the University of Toronto often have difficulty navigating the library and its resources. Orientation activities at the Engineering \& Computer Science Library are designed to introduce students to the library in an informal and entertaining way. In 2017, as a result of dropping interest in previous years' orientation activities, librarians at the Engineering \& Computer Science Library collaborated with instructors and staff in the Faculty of Applied Science and Engineering to develop an orientation activity grounded in curriculum and based on the popular escape room game. Core library services and engineering resources were used to build a challenging program that introduced students to basic, but essential, research skills. Voluntary student participation in the game exceeded previous years' participation and all expectations of the game designers.
\end{abstract}

Keywords: library orientation, first-year students, lifelong learning, information literacy, escape room

\section{INTRODUCTION}

With few exceptions, incoming first-year students arrive at university without a developed ability to locate, assess, and deploy scholarly information [14, 6, 13]. Surveys of engineering faculty suggest this gap in information literacy is also true of students in first-year engineering programs [4, 11]. Perhaps the problem is even more acute in technological disciplines as forms of engineering information (patents, standards, technical reports, conference proceedings, etc.) are less likely to have been addressed in secondary school STEM curriculum [8, 12, 10] leaving first-year engineering students at a disadvantage. The steep slope of skill development these students need to climb before making design decisions grounded in evidence has been understood as a key barrier to student success $[9,10]$.
In an attempt to close this gap, engineering librarians, first-year engineering faculty, and departmental staff collaborated in the development of an outreach project to introduce essential engineering research skills in the first weeks of the first-year engineering experience. To capture the imagination of incoming students and to reflect one of the core pedagogical approaches of engineering education - problem-solving - this project drew on the popularity of the escape room game.

Research indicates that in both online and physical library spaces, the gamification of instruction is an effective approach to strengthen student engagement [1, 17]. Gamification works by introducing an intrinsic or extrinsic element of motivation [3], a reward, that may be difficult to offer through a more traditional instructional approach. In addition, this "direct purposeful experience" [5] with library resources paired with the kind of collaborative and problem-based learning that the escape room model can support [15], delivers a powerful framework for information sharing already being used effectively by academic libraries [15] and engineering instructors [18] around the world.

This paper will address a process of consultation, game design, implementation, and assessment that took place between the Faculty of Applied Science and Engineering (FASE) and the Engineering and Computer Science Library (ECSL) at the University of Toronto (U of T). It will provide an overview of the design process highlighting challenges faced during each stage of development with a view to encouraging and supporting the development of similar partnerships and programming in peer institutions across the country.

\section{BACKGROUND}

The Engineering \& Computer Science Library at U of $\mathrm{T}$ is located in the Sandford Fleming Building, one of the main engineering buildings on campus. It supports research, teaching, and learning within FASE and the Department of Computer Science. For the purposes of this project, students within FASE were targeted. In 2016- 
2017, FASE enrollment included 5441 undergraduate and 2365 graduate students [7]. Just over 1000 undergraduate students arrived at $\mathrm{U}$ of $\mathrm{T}$ for the first time in September 2017 [7]. Librarians at ECSL are assigned responsibility for supporting each engineering department with in-class instruction, consultations, and the development and maintenance of a rich resource collection. To supplement this core work at ECSL and the work at U of T's 43 other campus libraries, an annual Chief Librarian's Innovation Grant is made available to library staff to fund new programs and initiatives, especially those that build partnerships beyond the library system. It is this grant that made the 2017 outreach project possible.

While undergraduate student participation in noncompulsory skill development workshops is generally low [2], the ECSL has used the principles of gamification in library instruction to run popular orientation activities for several years, most recently in the form of an Amazing Race-type scavenger hunt. The goal of orientation programming at ECSL is to introduce new students to engineering information, as well as library services like course reserves and reference and research help. While attendance numbers have fluctuated over the years, the past two years have been precipitously low.

\section{CONSULTATION}

The assembly of a game design team was not difficult as communication between librarians, course instructors and departmental staff is relatively strong in this engineering program. Invitations were sent to two instructors of the large first-year design courses, an engineering communications instructor, a staff member from the First-Year Office, and a staff member from the Education Technology Office. Four of five invited team members were able to take part in the design process.

While the development of an escape room game was the proposed approach, alternate solutions to address falling interest in the library's non-compulsory workshops were considered. The first was the requirement of firstyear student participation in library orientation programming. Since 2010, first-year faculty in the Division of Engineering Science and ECSL librarians have been co-planning a compulsory, gamified "Library Studio" introducing students to services and resources necessary for the successful completion of their design projects. Narrowly focused on the learning outcomes of a specific project, this workshop takes place each fall and introduces students to engineering information through a timed activity during which information (and skills) are gathered as students move level by level to an ultimate goal. While this compulsory program has been successful in producing the required results, requiring participation in an orientation activity would not be in the irreverent spirit of F!rosh Week.
A second solution considered was the cancellation of the library's orientation week programming altogether. In previous years, first-year students were invited to visit the library and take part in the programming as part of an annual and official "Fun with Faculty" day. In 2017, this faculty-focused program was cancelled and there was no longer a "natural" place for the library in F!rosh Week. Cancellation and a re-deployment of resources was considered. However, outreach to students in the early days of their undergraduate experience remained a priority for the library. This desire to begin building relationships with students as early as possible, led us away from cancellation.

Ultimately, the design team decided to move forward with a new program that could stand out in a sea of other dynamic F!rosh week offerings. Building a strong culture of engagement, a key priority laid out in the University of Toronto Libraries' Strategic Plan [16], is work that ECSL strives to sustain - maintaining excellence in the delivery of services - and renew - as new students enter the stage and work to create the experience they want to have. Andrew Walsh [17] believes that through play, "an organization like a library can engage "the whole person, building a culture of commitment, trust, and creativity." With an eye to engaging the whole person of the individual incoming students and a decision to make something new, game design got underway.

\section{GAME DESIGN}

First identifying priority learning outcomes, the team next developed a game narrative that would engage the imagination of the first-year undergraduate cohort.

While fairly demanding learning outcomes were tabled, the design team reached consensus on a set of learning outcomes that were simple but could have a profound impact on a student's ability to hit the ground running in the context of information seeking, evaluation, and use. These key learning outcomes included:

- Find the library

- Ask a question at the Reference Help Desk

- Use the library catalogue to find a book by title

- Use a call number to find a book on the shelf

- Use a database to access a technical standard

- Find the Course Reserves/Short Term Loan collection

While these are fairly low-level skills, they are ones that all members of the design team recognized as key skills that many incoming first year students struggled with. For example, even though ECSL is located within the Sandford Fleming Building, one of the main engineering buildings on campus, many first year students often do not know where ECSL is located, that there are 
librarians who can help them with their research, or that the library even exists.

Narrative design began with a number of story threads and through subsequent conversations a single narrative began to emerge. While discussing the 2017 F!rosh orientation week theme of Star Wars, team members realized the Sandford Fleming Building fire of 1977 and the premiere of Star Wars took place in the same year. This intersection would offer an interesting landscape for game play. Set in the present day, the story asked students to help solve the mystery of the great fire and uncover the Star Wars-connected truth behind the disappearance of a once promising electrical engineering professor by using engineering information gathered in the library collection.

Designing a typical escape room where players are locked inside a game space that contains all required clues was not possible in the open concept space of ECSL. As an alterative, the team decided to purchase "breakout boxes" from a company called BreakoutEDU and build a game where teams of players compete to solve a series of puzzles in order to open a locked box. The fastest team to complete the game would take home a grand prize.

The breakout box in this game was secured with four combination locks including a 3-number, 4-number, 5letter, and directional-type lock to provide ample problem-solving opportunities. Next, through an iterative process, team members identified combinations for each lock drawn from elements of the engineering information students would need to locate. Once four locks and four combinations were identified, a set of clues were developed to lead players from the initial prop - a course syllabus for a fictional electrical engineering course taught by the missing professor - through a series of activities that would deliver all the puzzles pieces required to open each lock. The clues and combinations for each lock are included in Table 1.
Table 1: The clues and combinations for the game.

\begin{tabular}{|c|c|c|c|}
\hline $\begin{array}{l}\text { Clue } \\
\# \\
\end{array}$ & Clue & $\begin{array}{l}\text { Location of } \\
\text { Clue } \\
\end{array}$ & Combination \\
\hline 1 & $\begin{array}{l}\text { UL Standard: } \\
\text { Safety for } \\
\text { Durability of Fire } \\
\text { Resistive Coatings } \\
\text { and Materials }\end{array}$ & $\begin{array}{l}\text { Included in } \\
\text { course syllabus } \\
\text { under } \\
\text { "Suggested } \\
\text { Reading" }\end{array}$ & $\begin{array}{l}\text { Combination: } \\
2431\end{array}$ \\
\hline 2 & $\begin{array}{l}\text { Periodic table of } \\
\text { elements with } \\
\text { three symbols out } \\
\text { of order. }\end{array}$ & $\begin{array}{l}\text { Full table } \\
\text { posted in } \\
\text { library and } \\
\text { required } \\
\text { elements } \\
\text { printed in } \\
\text { syllabus } \\
\end{array}$ & $\begin{array}{l}\text { Combination: } \mathrm{Kr} \\
\mathrm{I} \mathrm{Ne}\end{array}$ \\
\hline 3.a. & $\begin{array}{l}\text { Catalogued and } \\
\text { shelved } \\
\text { engineering lab } \\
\text { book containing } \\
\text { hidden Greek } \\
\text { letters }\end{array}$ & $\begin{array}{l}\text { Included in } \\
\text { course syllabus } \\
\text { under } \\
\text { "Required } \\
\text { Reading" }\end{array}$ & N $\psi$ \\
\hline 3.b. & $\begin{array}{l}\text { Catalogued and } \\
\text { shelved in Course } \\
\text { Reserves/Short } \\
\text { Term Loan; a box } \\
\text { containing cypher } \\
\text { and black light } \\
\end{array}$ & $\begin{array}{l}\text { Included in } \\
\text { course syllabus } \\
\text { under } \\
\text { "Required } \\
\text { Reading" }\end{array}$ & $\begin{array}{l}\mathrm{N}=50 \\
\Psi=700 \\
\text { Combination: } \\
750\end{array}$ \\
\hline 4. & $\begin{array}{l}\text { Figure of joystick } \\
\text { wiring diagram }\end{array}$ & $\begin{array}{l}\text { Included in } \\
\text { course syllabus }\end{array}$ & $\begin{array}{l}\text { Up, left, down, } \\
\text { left, right }\end{array}$ \\
\hline
\end{tabular}

Three versions of the game were created with each version including a syllabus with different required and suggested readings and a variation in each wiring diagram to allow multiple teams to play at the same time and limiting the ability for clues to be shared between teams. These versions also ensured each game component would be available for each team as needed.

As well as developing puzzles and clues, the design team also sought to encourage interaction with library staff. Engineering students, known for their independence, sometimes need to be encouraged to reach out for help. To promote this help-seeking, one minute was removed from each team's final time if one question was asked at the Reference Help Desk. If two questions were asked, the recorded time remained unchanged. If a team needed to ask for help three or more times, one minute would be added for each additional question. Teams were also given a 1-hour time limit to complete the game, but were allowed to unofficially continue if there was no other team scheduled in the time period afterwards. 
Two rounds of game testing drew on staff and faculty volunteers who visited the library for an hour of play and feedback. Testing allowed the design team to identify weaknesses or failures, to ensure the game provided opportunities for planned learning, to determine the ideal level of difficulty, and to plan requirements for game implementation and game management.

\section{GAME IMPLEMENTATION}

The game was marketed to students using posters, emails (including emails to first year students through the "Personal Librarian" program), and digital signage. Faculty and staff members of the design team also encouraged their students to take part extending the library's outreach beyond its typical capabilities. Reference Help Desk staff, which included librarians and Graduate Student Library Assistants (GSLAs), managed the sign-up and game play. Teams of 3-5 players were able to sign up in person or over the phone at the Reference Help Desk, and teams played only when the Reference Help Desk was open, which included evenings and weekends. This was done to ensure dedicated staff would be available during game play to give instructions, facilitate game play, give hints when needed, and to reset the games when they were successfully completed or the time was up. Play was not limited to first-year students, and all levels of students were allowed to play. The Reference Help Desk is also where students (and any other library user) can ask reference or research questions and receive help or instruction on the spot, and the design team wanted students to get used to using this service. Detailed written instructions on how to manage the game were given to all Reference Help Desk staff, and inperson training was also provided. An excel file was used to kept track of registration as well as the final times. Loan Services Desk staff were also trained to support game play as they would have to facilitate the retrieval of one of the clues located in Course Reserves/Short Term Loan, which is kept in a staff area behind the Loan Services Desk not accessible by library patrons.

Teams began each game at the Reference Help Desk where they were shown the breakout box and provided with the game instructions and the storyline for the game, setting the scene. It was made clear to players that this was not a typical escape room game and that ransacking the library looking for clues would not be useful, and would result in the game being stopped. Players were also told that all clues could be found inside the ECSL or online. This was done as the "Required Readings" listed in the syllabus (lab book and Course Reserves/Short Term Loan item) had titles similar to those found at other libraries at $\mathrm{U}$ of $\mathrm{T}$, and the design team felt it was necessary to reduce any possible confusion that could lead to players leaving the library while the game was being played. Stopwatches were used to keep track of the time.
The game was determined to be completed when the team returned to the Reference Services Desk with the opened box, at which time the stopwatch was stopped. A leaderboard located near the library entrance was updated daily with the completion rate of the game, and was updated as needed when the previous fastest time was bested. The leaderboard served as both inspiration to currently competing teams and promoted the game to other library visitors.

\section{RESULTS AND DISCUSSION}

Between September 11, 2017 and September 30, 2017, 74 teams and a total of 293 students played the game. The completion rate is shown in Fig. 1. Eighty-six percent of the teams completed the game, however only $62 \%$ completed within the one hour allotted. Participation exceeded any "Fun with Faculty" orientation day activity ECSL had participated in in the past, although in this case the activity was available over an extended period of time instead of one or two time periods in one day, as was the case with "Fun with Faculty."

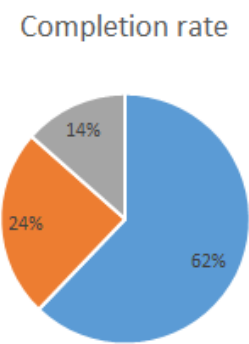

- Completed in less than 1 hour I I Completed but took mor ethan 1 hour " Did not complete

Fig. 1. Completion rate for the game between September 11 and September 30, 2017.

The fastest team completed the game in 21 minutes 11 seconds, and their final time was adjusted to 20 minutes 11 seconds because they asked one question during game play. A total of 130 hints were given during the three weeks of game play, modeling interactions design team members hope to see continuing throughout the school year. Some teams required 0 hints, while one team required 5 hints, demonstrating a range of needs. Many of the hints involved the location of Course Reserves/Short Term Loan within the library, as some groups did not know where it was, while others did not notice that this was the location indicated in the library catalogue record. The other main pain point was the clue for the lettered lock - many teams did not notice the posted periodic table or the clue within the syllabus for this lock, and needed some help understanding the clues and possible solution. 
Student feedback about the game was recorded and was generally positive. Some teams that did not complete the game asked to play the game again. Teams that did complete the game asked if they could play the other versions of the game until they discovered that each version differed only slightly. Many comments indicated that the game was fun and challenging, and most were very enthusiastic about the game. One group mentioned that they were learning a lot about the library. There was one group that was disappointed that they were not locked in the library, similar to a typical escape room, but none of the other groups seemed to mind that it was not that traditional model.

In terms of staff feedback, scheduling was highlighted as an issue, as when all three games were scheduled back to back, it did not give staff much time to reset the game. This caused the next game to start late. This only happened a few times, but was stressful for the staff member involved. Scheduling the games only every second hour or only allowing 50 minutes of game play to allow time for the game to be reset are two ways the problem might be circumvented in the future.

An additional problem resulted when the Reference Help Desk staff was queried by students not participating in the game (not entirely surprising, as that is the service point's main purpose) as students playing the game may have had to wait for help. This was remedied during game play with time being taken off to adjust for the time the team had to wait. Other occasional problems included one of the clues not being put back in the correct spot, and there were multiple teams that pulled all versions of one clue, confusing themselves and hindering any teams that were playing at the same time. Some judgement was required in order to rectify these issues, and mostly resulted in time being taken off.

Assessment of the game was through participation numbers, the success of teams' ability to complete the game, and feedback from the players. The goal was to have at least 20 people play the game, and that goal was achieved. While the game needed to be challenging enough to keep students' interest, it was not set out to be as challenging as traditional escape rooms which can have very low completion rates. That is why groups were encouraged to continue to play even if time was up as long as there was not another team waiting. The aim was to have the students gain some basic knowledge of the library, and a low success rate would not achieve that goal. The design team also wanted students to have a positive experience in the library and associate it with good thoughts rather than frustration. Since the design team wanted the students to leave the game with an understanding of basic library services and resources, having students successfully complete these challenges was the best measure of the success of the game. While the overall completion rate was only $86 \%$, many of teams that did not complete the game were still able to complete many of the challenges. One of the most challenging clues was the one connected to the chemicals in the syllabus and the periodic table, and that was not related to library function. Eliminating this challenge or any similar ones that are not directly connected to the library or its services in the future was considered by the design team. With the large number of students in all years of undergraduate studies who have reported not knowing that research help is available at the Reference Help Desk and that librarians are available for research consultations, the success of 2017 orientation programming signals that this trend may be lessened in coming years.

While the game focused on fundamental skills necessary for engineering research, there is no expectation that the students who played the game are now expert, or even intermediate, researchers. However, they left the game with some foundational knowledge and skills that additional information literacy instruction can be built upon, and gave them a head start when working on their design projects.

\section{CONCLUSION}

The escape room game provided a positive experience for students and library staff. Collaborating with faculty and staff from FASE enabled the librarians to focus efforts on creating a game targeted at the most relevant, foundational library skills that would aid students in succeeding in their first year courses. The turnout and the completion rate for the game reached the goals set out when making the game, and the feedback was generally positive, indicating that it was successful in terms of creating a welcoming introduction to the library and its resources.

ECSL is hoping to offer another escape room type game using the breakout boxes in September 2018, and other libraries on campus are also looking at offering their own versions of an escape room or breakout game. This type of program offers an enjoyable introduction to the library and its services, while also steering students toward important library resources and services, and the authors plan to capitalize on that and on the popularity of escape room games while they remain of interest to engineering students.

\section{ACKNOWLEDGEMENTS}

This project was made possible by a University of Toronto Chief Librarian's Innovation Grant.

\section{References}

[1] Katelyn Angell and Katherine Boss, "Adapting the Amazing Library Race: Using problem-based learning in library orientations," College \& Undergraduate Libraries, vol. 23, no. 1, pp. 44-55, 2016. 
[2] Juliey Beckman and Gerry Rayner, "Embedding academicprofessional collaborations that build student confidence for essay writing: Student perceptions and quality outcomes. A Practice Report," Student Success, vol. 2, no. 2, pp. 83, 2011.

[3] Patrick Buckley and Elaine Doyle, "Gamification and student motivation," Interactive Learning Environments, vol. 24, no. 6, pp. 1162-1175, 2016.

[4] Sophie Bury, "Faculty attitudes, perceptions and experiences of information literacy: a study across multiple disciplines at York University, Canada," Journal of Information Literacy, vol. 5, no. 1, pp. 45-64, 2011.

[5] Edgar Dale, Audio-Visual Methods in Teaching. New York, NY: Dryden Press, 1969 (3rd ed.), 719 pp.

[6] Jenny Ellis and Fiona Salisbury, "Information literacy milestones: building upon the prior knowledge of first-year students," The Australian Library Journal, vol. 53, no. 4, pp. 383-396, 2004.

[7] Faculty of Applied Science and Engineering, Annual Report 2017: Performance Indicators. Toronto, ON: University of Toronto, 2018, $178 \mathrm{pp}$. Available as of May 5, $2018 \quad$ from http://www.engineering.utoronto.ca/about/annual-reports/

[8] Michael Hacker and Moshe Barak, "Important engineering and technology concepts and skills for all high school students in the United States: Comparing perceptions of engineering educators and high school teachers," Journal of Technology Education, vol. 28, no. 2, pp. 31-52, 2017.

[9] Nora Honken and Patricia AS Ralston, "Freshman engineering retention: A holistic look," Journal of STEM Education: Innovations and Research, vol. 14, no. 2, pp. 29-37, 2013.

[10] Elizabeth Kuley, Sean Maw, and Terry Fonstad, "Understanding Barriers to Student Success: What Students Have to Say," in Proc. CEEA Canadian Engineering Education Conf., CEEC16, (Dalhousie, NS; 19-22 June 2016), 6 pp. 2016.
[11] Gloria J Leckie and Anne Fullerton, "Information literacy in science and engineering undergraduate education: faculty attitudes and pedagogical practices," College \& Research Libraries, vol. 60, no. 1, pp. 9-29, 1999.

[12] Nathan Mentzer and Michael J Fosmire, "Quantifying the information habits of high school students engaged in engineering design," Journal of Pre-College Engineering Education Research, vol. 5, no. 2, pp. 22-34, 2015.

[13] Dianne Mittermeyer, "Incoming first year undergraduate students: How information literate are they?,” Education for Information, vol. 23, no. 4, pp. 203-232, 2005.

[14] Fiona Salisbury and Sharon Karasmanis, "Are they ready? Exploring student information literacy skills in the transition from secondary to tertiary education," Australian Academic \& Research Libraries, vol. 42, no. 1, pp. 43-58, 2011.

[15] Eng Ung and Fiona Salisbury, "There’s no escape: Using escape room design principles to engage library users," ALIA Information Online 2017 Conference, Sydney, Austrailia. Unpublished conference paper.

[16] University of Toronto Libraries, Charting Our Future: 2016 Update. Toronto, ON: University of Toronto, 2016, 12 pp. Available as of May 5, 2018 from https://onesearch.library.utoronto.ca/strategicplan/strategic-plan-2013-2018

[17] Andrew Walsh, "The potential for using gamification in academic libraries in order to increase student engagement and achievement," Nordic Journal of Information Literacy in Higher Education, vol. 6, no. 1, pp. 39-51, 2014.

[18] Patrick Williams, "Using escape room-like puzzles to teach undergraduate students effective and efficient group process skills” In 2018 IEEE Integrated STEM Education Conference (ISEC), (Princeton, NJ; 10 March 2018), 4 pp., 2018. 